NASCIMENTO, I.B.; FARIAS, C.H.A.; SILVA, M.C.C.; MEDEIROS, J.F.; ESPÍNOLA SOBRINHO, J.; NEGREIROS, M.Z. Estimativa da área foliar do meloeiro. Horticultura Brasileira, Brasília, v. 20, n. 4, p. 555-558, dezembro 2002.

\title{
Estimativa da área foliar do meloeiro
}

\author{
Iarajane B. do Nascimento ${ }^{1}$; Carlos Henrique A. Farias ${ }^{1}$; Marcelo Cleon C. Silva ${ }^{1}$; José Francismar de \\ Medeiros $^{1}$; José Espínola Sobrinho' ${ }^{1}$; Maria Zuleide de Negreiros ${ }^{1}$ \\ ${ }^{1}$ ESAM, C. Postal 137, 59.600-970 Mossoró - RN; E-mail: iarajane@hotmail.com
}

\begin{abstract}
RESUMO
Estimou-se a área foliar da cultura do melão (Cucumis melo, L.) cv. Gold Mine, submetido a lâminas de irrigação variando de $55 \%$ a $130 \%$ da necessidade híbrida da cultura, usando água de baixa e alta salinidade. Foi coletada uma planta em cada parcela, aos 19; 26; 34; 40 e 50 dias após a semeadura, onde se determinou o número e a área foliar total e as suas dimensões, e a área foliar individual até 24 folhas por planta. Os resultados evidenciaram que existe uma correlação parcial entre a área foliar total da planta e o número de folhas de $0,945^{* *}$, e a equação de regressão obtida foi $\mathrm{AF}=108 \mathrm{NF}-516$, com $r^{2}=0,95$. A comparação conjunta das equações obtidas para cada época mostra que pelo menos uma relação entre largura $(L)$ e área foliar (AF) diferenciaram das demais, embora a relação que assume os dados como um todo, apresente um alto valor para o coeficiente de determinação, sendo a seguinte: $\mathrm{AF}=0,826 \mathrm{~L}^{1,89}\left(\mathrm{r}^{2}=0,97\right)$.
\end{abstract}

Palavras-chave: Cucumis melo L., desenvolvimento vegetativo, salinidade.

\begin{abstract}
Estimation of melon plant leaf area

The leaf area of the Gold Mine melon was estimated when submitted to irrigation water levels varying from $55 \%$ to $130 \%$ of the hydric necessity of the crop, utilizing low and high salinity water. One plant per plot was collected at $19 ; 26 ; 34 ; 40$ and 50 days after sowing, obtaining data of length, width, total leaf area, number of leaves, and individual leaf areas up to 24 leaves per plant. The results indicated that a partial correlation between the total plant leaf area (AF) and the number of leaves (NF) exists, with $\mathrm{r}^{2}=0.95^{* *}$, and the regression equation $\mathrm{AF}=108 \mathrm{NF}-516$, with $\mathrm{r}^{2}=0.95$. The comparison of the models showed that at least one relation between leaf width (L) and leaf area (AF) differentiated from the others, even though the relation that assumes the whole data set $\left(\mathrm{AF}=0,826 \mathrm{~L}^{1,89}\right.$; $r^{2}=0.97$ ) has a high determination coefficient.
\end{abstract}

Keywords: Cucumis melo L., plant growth, salinity.

(Recebido para publicação em 6 de novembro de 2000 e aceito em $1^{0}$ de agosto de 2002)

\begin{abstract}
A cultura do melão (Cucumis melo, L.) ocupa posição de grande importância no Nordeste, principalmente no Rio Grande do Norte, devido ao seu grande potencial produtivo. Nestes últimos anos, a área média cultivada no Estado tem ficado ao redor de 6.000 ha e a produtividade média acima de 20.000 $\mathrm{kg} / \mathrm{ha}$, embora seja comum os grandes e médios produtores alcançarem rendimento superiore a $30.000 \mathrm{~kg} / \mathrm{ha}$.
\end{abstract}

A área foliar do meloeiro é uma importante medida para avaliar a eficiência quanto à fotossíntese e, consequentemente, na produção final (Costa, 1999), além de servir para estimar a necessidade hídrica da cultura (Allen et al., 1998). Sua avaliação durante todo o ciclo da cultura é de extrema importância para que se possa modelar o crescimento e o desenvolvimento da planta e, em conseqüência, a produtividade e a produção total da cultura (Teruel, 1995).

Rocha et al. (2000) estudando o comportamento de cultivares de melão Pele de sapo submetidas às condições de salinidade, observaram que, a área foliar e a produção total de biomassa do meloeiro apresentaram uma redução progressiva, à medida que aumentou a salinidade da água de irrigação. A lâmina de irrigação inferior à necessidade hídrica da cultura produz estresse hídrico à planta afetando número e tamanho das folhas e área foliar total (Hernandez, 1995).

Existem inúmeras possibilidades para se determinar a área foliar. Pela facilidade e por ser não-destrutivo, os mais utilizados são o comprimento ao longo da nervura principal, a largura máxima e as relações entre essas medidas. Tivelli et al. (1997) estabeleceram como metodologia para estimativa da área foliar do pimentão, a medição da largura das folhas. Então, através de uma equação do tipo polinômio de segundo grau, estima-se a área de cada folha a partir da medida de sua largura, obtendo-se a área foliar da planta pelo somatório.

$\mathrm{Na}$ estimativa da área dos folíolos do morangueiro, Strik \& Proctor (1985) observaram que o produto do comprimento pela largura dos mesmos, como variável independente na equação de regressão, mostrou-se superior na ca- pacidade de predição e na precisão, quando comparada ao uso do comprimento ou largura. Pires et al. (1999) também trabalhando com morangueiro, verificaram que para a estimativa da área foliar total são necessárias medidas do comprimento e da largura dos folíolos, em amostra representativa, além da contabilização do número de folhas.

O objetivo deste trabalho foi determinar uma equação que permita estimar a área foliar do meloeiro a partir do número de folhas e de suas dimensões, sob diferentes lâminas de irrigação, e com água de baixa e alta salinidade.

\section{MATERIAL E MÉTODOS}

Este trabalho foi conduzido de 11 de novembro de 1998 a 20 de janeiro de 1999, na Fazenda São João Ltda., localizada no município de Mossoró (RN) (5'12' S, 3712' WGr., $18 \mathrm{~m}$ de altitude), utilizando-se o melão amarelo, híbrido Gold Mine.

Os dados foram coletados num experimento que compreendeu 36 parcelas, com cada unidade experimental constituída de três fileiras de seis metros 
Tabela 1. Valores médios da área foliar, do número de folhas por planta, largura e comprimento e área individual de cada folha para cada época de amostragem. Mossoró, ESAM, 1999

\begin{tabular}{ccccccc}
\hline Época & $\begin{array}{c}\text { Área foliar por } \\
\text { planta }\left(\mathbf{c m}^{2}\right)^{*}\end{array}$ & $\begin{array}{c}\mathbf{N}^{\circ} \text { de folhas por } \\
\text { planta (unidade) }\end{array}$ & $\begin{array}{c}\text { Largura da folha } \\
\left(\mathbf{c m}^{\mathbf{2}}\right)^{* *}\end{array}$ & $\begin{array}{c}\text { Comprimento } \\
\mathbf{d a} \text { folha }\left(\mathbf{c m}^{\mathbf{2}}\right)^{* *}\end{array}$ & $\begin{array}{c}\text { Área da folha } \\
\left(\mathbf{c m}^{\mathbf{2}}\right)^{* *}\end{array}$ \\
\hline 19 & $373 \pm 19$ & $7,5 \pm 0,27$ & $6,8 \pm 0,41$ & $5,8 \pm 0,27$ & $50,4 \pm 4,50$ \\
26 & $1728 \pm \quad 86$ & $21,5 \pm 0,69$ & $10,6 \pm 0,27$ & $6,8 \pm 0,14$ & $80,1 \pm 3,51$ \\
34 & $4911 \pm 332$ & $52,0 \pm 2,36$ & $14,0 \pm 0,18$ & $8,8 \pm 0,10$ & $123,6 \pm 2,88$ \\
40 & $8389 \pm 484$ & $83,0 \pm 4,09$ & $14,8 \pm 0.21$ & $9,8 \pm 0,12$ & $142,6 \pm 3.86$ \\
50 & $10011 \pm 559$ & $95,5 \pm 5,03$ & $14,8 \pm 0,19$ & $9,9 \pm 0,12$ & $136,5 \pm 3,21$ \\
\hline
\end{tabular}

* $\mathrm{N}$ de amostras por época $19 ; 26 ; 34 ; 40$ e 50 dias após a semeadura.

** $\mathrm{N}$ de amostras por $19=86,26=249,34=249,40=285$ e $50=281$

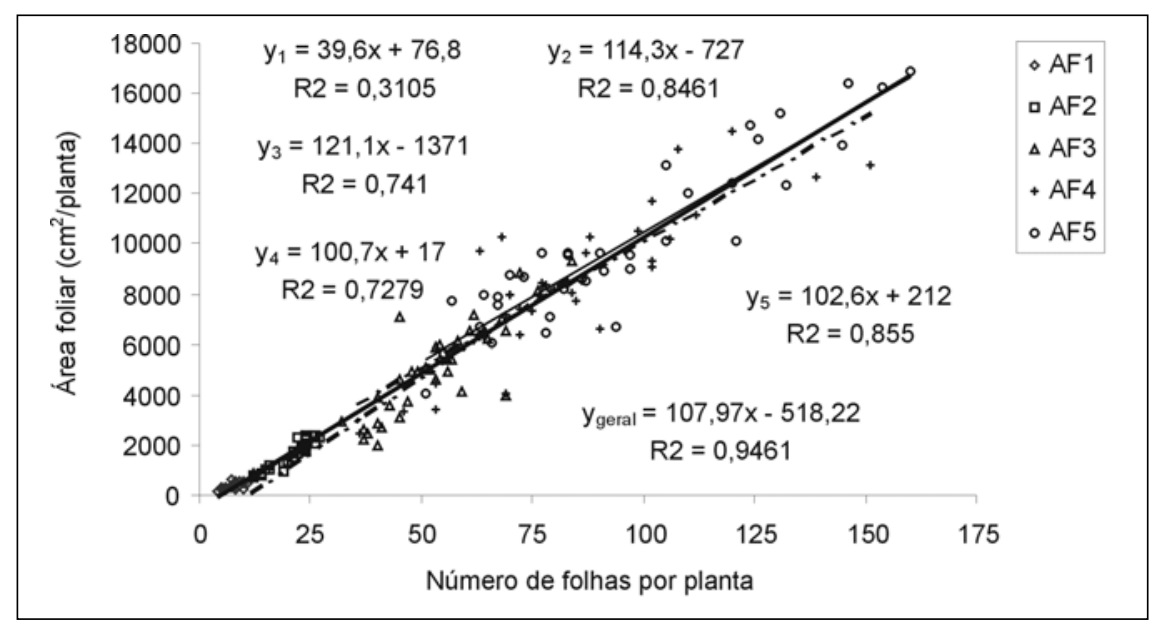

Figura 1: Área foliar do meloeiro em função do número de folhas na planta, para diferentes épocas de amostragem. $(\mathrm{AF} 1=19, \mathrm{AF} 2=26, \mathrm{AF} 3=34, \mathrm{AF} 4=40, \mathrm{AF} 5=50$ dias $)$. Mossoró, ESAM, 1999.

com espaço de $2 \mathrm{~m}$ e duas plantas a cada $60 \mathrm{~cm}$. O delineamento experimental utilizado foi um esquema fatorial $2 \times 6$ em blocos completos casualizados. Os tratamentos aplicados foram 6 lâminas de irrigação, representando 55; 70; 85; 100; 115 e 130\% da necessidade hídrica da cultura, o que correspondeu a 146; 186; 226; 266; 306 e 346 mm durante o ciclo. A água de irrigação foi oriunda de dois poços, uma de origem arenítica (condutividade elétrica - $\mathrm{CE}=0,55$ dS.m $\left.{ }^{-1}\right)$ e a outra do calcário Jandaíra (condutividade elétrica - $\mathrm{CE}=2,65$ $\left.\mathrm{dS} \cdot \mathrm{m}^{-1}\right)$. As irrigações foram realizadas por meio de gotejadores, aplicando-se a lâmina pré-estabelecida para cada tratamento diariamente.

As amostragens de plantas foram efetuadas ao longo do ciclo da cultura, iniciando-se no $19^{\circ}$ dia após a semeadura, e as demais sendo realizados aos 26; 34 ; 40 e 50 dias. Em cada época era coletada uma planta de cada parcela experimental.
Foram medidos o comprimento (C), a largura (L) e área foliar (AF) de cada folha da planta. Quando a mesma apresentou mais de 24 folhas, selecionou-se ao acaso este número, como também foi medida a área foliar total de cada planta, através de um integrador de área foliar LI 3100 da LICORâ.

Com os dados da área foliar total de cada planta, número de folhas por planta e área foliar unitária e sua dimensão foi realizada a análise de regressão, utilizando o software Table Curve (Jandel Scientific, 1991). A escolha do modelo foi feita entre os modelos simples, cujo teste $\mathrm{F}$ e coeficiente de determinação apresentaram maiores valores. Para comparar as relações entre as variáveis analisadas entre as épocas, níveis de salinidade e lâminas de irrigação, adotou-se o procedimento de análise conjunta de modelos no módulo regressão linear do software SAEG ${ }^{\circledR}$ v. 4.0.

\section{RESULTADOS E DISCUSSÃO}

O número de folhas por planta, bem como a área foliar cresceu continuamente até os 50 dias, porém a largura da folha estabilizou-se a partir dos 40 dias (Tabela 1). Houve correlação parcial entre área foliar total da planta e o seu número de folhas $(\mathrm{r}=0,95)$, sendo altamente significativo. $\mathrm{O}$ estudo de análise de regressão e de variância, para comparar igualdade entre os modelos para os dados coletados aos 19; 26; 34; 40 e 50 dias após a semeadura, revelou que se pode estabelecer uma relação única, independente da época, da lâmina de irrigação e da salinidade da água, indicando que as mesmas apresentaram comportamento semelhante, ou seja, foram afetados igualmente pelos níveis de salinidade e lâmina de irrigação nas diferentes épocas estudadas, concordando com os resultados obtidos por Rocha et al. (1999). A equação de regressão obtida foi $\mathrm{AF}=108^{* *} \mathrm{NF}-518$, com $\mathrm{r}^{2}=0,95$, sendo AF a área foliar total da planta e NF o número de folhas. Verificou-se que o número de folhas variou de 5 a 160 e a área foliar ficou na faixa de 100 a $17.000 \mathrm{~cm}^{2} /$ planta e que as curvas para cada época são bem próximas da curva que engloba todas as épocas (Figura 1).

Não houve efeito da lâmina e salinidade da água de irrigação nas relações entre área e dimensões das folhas. O modelo tipo potencial é o que melhor se ajusta às relações entre área foliar e suas dimensões para todas as épocas (Figura 2 e 3 ) e que existe uma maior correlação com a largura (L) do que com o comprimento (C). Esta me- 
Tabela 2. Parâmetros da equação de regressão para diferentes idades da planta de melão, a área e a largura foliar. Mossoró, ESAM, 1999.

\begin{tabular}{|c|c|c|c|c|c|}
\hline \multirow{2}{*}{ Época } & \multicolumn{2}{|c|}{ Parâmetros \# } & \multirow{2}{*}{$\mathbf{R}^{2}$} & \multirow{2}{*}{$\mathrm{N}^{\circ}$ de dados } & \multirow{2}{*}{$\mathbf{F}$} \\
\hline & A & B & & & \\
\hline 19 & 0,787 & 1,92 & 0,976 & 86 & $2659^{* *}$ \\
\hline 26 & 0,854 & 1,88 & 0,968 & 249 & $5755^{* *}$ \\
\hline 34 & 0,904 & 1,85 & 0,925 & 274 & $2986^{* *}$ \\
\hline 40 & 0,652 & 1,98 & 0,957 & 285 & $5006^{* *}$ \\
\hline 50 & 0,905 & 1,85 & 0,935 & 281 & $3686^{* *}$ \\
\hline GLOBAL & 0,826 & 1,89 & 0,970 & 1175 & $32070 * *$ \\
\hline \multicolumn{3}{|c|}{ Comparação dos modelos entre as épocas } & & \multicolumn{2}{|c|}{$2,48^{*}$} \\
\hline
\end{tabular}

\#/ Modelo: $\mathrm{Y}=\mathrm{A} \mathrm{X}^{\mathrm{B}}$

*/ Significativo no nível de $5 \%$ de probabilidade para o teste Tukey.

**/ Significativo no nível de $1 \%$ de probabilidade para o teste de Tukey.

nor correlação com o comprimento pode-se atribuir à inserção do pecíolo no limbo foliar e à forma da folha ser aproximadamente cordiforme, o que dificulta a medida, cometendo-se erros na sua determinação (Figura 3 ).

A comparação conjunta dos modelos mostra que pelo menos uma relação entre largura (L) e área foliar (AF) se diferencia significativamente $(p<0,05)$ das demais, embora a relação que assume os dados como um todo, apresente um alto valor para o coeficiente de determinação $(0,97)$, podendo ser utilizada para o conjunto de dados (Tabela 2 ).

O expoente próximo de dois, para a relação entre área foliar e largura, é explicável pelo fato da área ser produto de duas dimensões lineares. Embora neste trabalho tenham sido estimados outros modelos, como aqueles testados por Pires et al. (1999) para o morangueiro, plantas cujas folhas são cordiformes, onde os mesmos não foram superiores ao potencial. A maior correlação da área foliar com sua largura deveu-se a esta dimensão ser mais estável e apresentar menor possibilidade de erro na sua medida, o que concorda com o obtido por Tivelli et al. (1997) que, estudando a cultura do pimentão, observaram uma alta correlação entre $\mathrm{L}$ e o produto $\mathrm{C} x$ L. Strik \& Proctor (1985) verificaram maior predição e precisão na estimativa da área dos folíolos do morangueiro através do produto do comprimento pela largura. Entretanto, Pires et al. (1999) encontraram semelhança entre o coeficiente de determinação, quando da utilização de $\mathrm{C}+\mathrm{L}$ e somente $\mathrm{L}$ na estimativa da área.
Figura 2: Área foliar unitária do meloeiro em função de sua largura, para diferentes épocas de amostragem $(\mathrm{AF} 1=19, \mathrm{AF} 2=26, \mathrm{AF} 3=34, \mathrm{AF} 4=40, \mathrm{AF} 5=50$ dias $)$. Mossoró, ESAM, 1999.

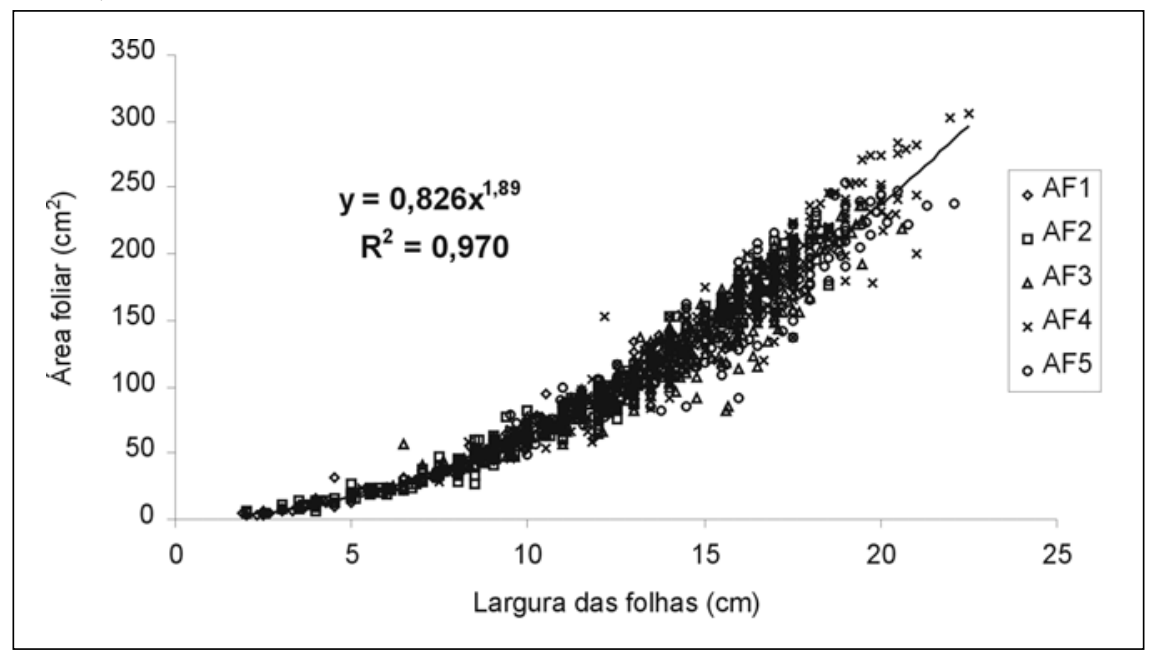

Figura 3: Área foliar do meloeiro em função do comprimento de folhas na planta, para diferentes épocas de amostragem $(\mathrm{AF} 1=19, \mathrm{AF} 2=26, \mathrm{AF} 3=34, \mathrm{AF} 4=40, \mathrm{AF} 5=50$ dias $)$. Mossoró, ESAM, 1999.

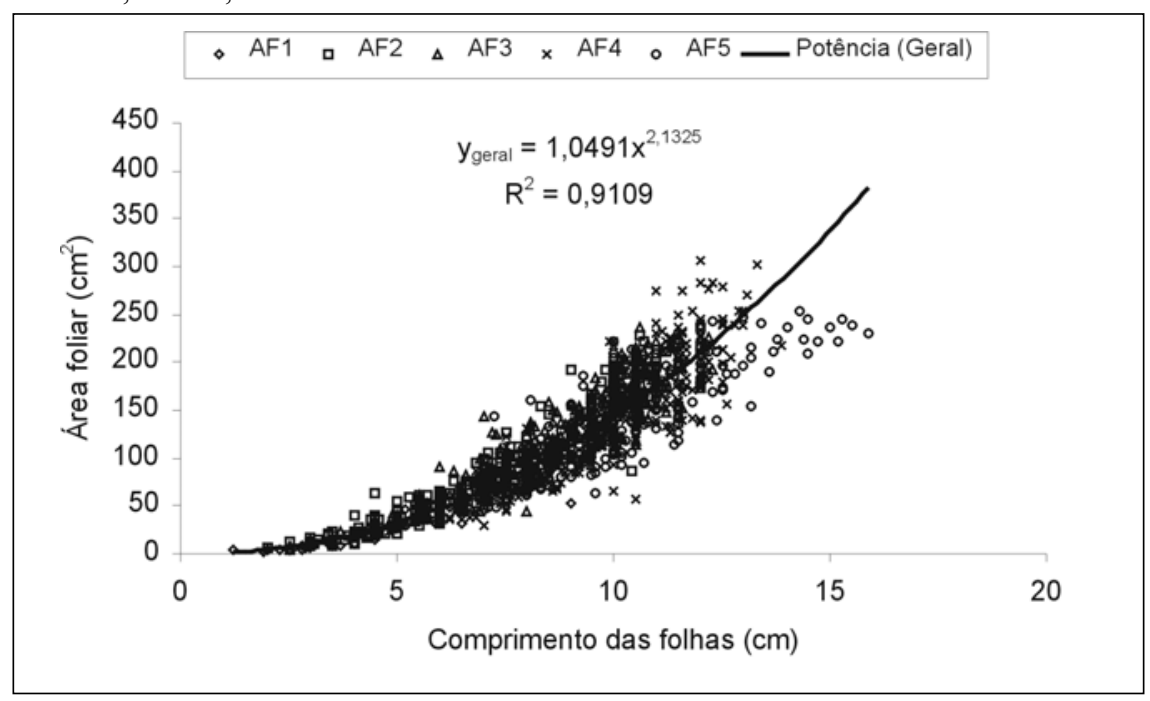


Embora a estimativa da área individual de cada folha, usando a medida de sua largura apresente maior coeficiente de determinação, a área foliar do meloeiro, pode ser estimada com precisão razoável a partir da contagem do número de folhas da planta, independentemente da salinidade da água e da lâmina de irrigação aplicados e idade da planta.

\section{LITERATURA CITADA}

ALLEN, R.G.; SMITH, M.; PEREIRA, L.S.; PRUIT, W.O. Proposed revision to the FAO: procedure for estimating crop water requeriments. In: INTERNATIONAL SYMPOSIUM ON IRRIGATION OF HORTICULTURAL, 2, 1996, Chania. Proceeding..., Leven, ISHS, 1996. p. 17-49.
COSTA, M.C. Efeitos de diferentes lâminas de água com dois níveis de salinidade na cultura do meloeiro. Botucatu, UNESP, 1999, 115 p. (Tese doutorado).

HERNANDEZ, F.B.T. Efeitos da supressão hídrica nos aspectos produtivos e qualitativos da cultura do melão. Piracicaba, ESALQ/USP, 1995 (Tese doutorado).

JANDEL SCIENTIFIC. User's Manual. California, 1991.280 p.

PIRES, R.C.M.; FOLEGATTI, M.V.; PASSOS, F.A. Estimativa da área foliar de morangueiro. Horticultura Brasileira, Brasília, v. 17, n. 2, p. 86-90, julho, 1999.

ROCHA, D.G.F.; HOLANDA, J.S.; MEDEIROS, J.F.; ALENCAR, R.D.; PORTO FILHO, F.Q.; ROCHA, A.A. Comportamento de cultivares de melão Pele de sapo submetidas a condições de salinidade. In: CONGRESSO BRASILEIRO DE FRUTICULTURA, 10, 2000, Fortaleza. Anais.. Fortaleza, SBF, 2000, CD-Rom.
STRIK, B.C.; PROCTOR, J.T.A. Estimating the area of trifoliate and unequally imparipinnate leaves of strawberry. Hortscience, v. 20, n. 6, p. 1072-1074, 1985.

TERUEL, D.A. Modelagem do indice de área foliar de cana-de-açúcar em diferentes regimes hidricos. Piracicaba, ESALQ, 1995, 93 p (Tese mestrado)

TIVELLI, S.W.; MENDES, F.; GOTO, R. Estimativa da área foliar do pimentão cv. Elisa conduzido em ambiente protegido (Capsicum annum L.). In: CONGRESSO BRASILEIRO DE OLERICULTURA, 38, 1997, Manaus. Suplementos..., Brasília: SOB, 1997. 